\title{
Ex vivo adenovirus mediated gene transfection of human conjunctival epithelium
} Jikui Shen, Neil Taylor, Linda Duncan, Imre Kovesdi, Joseph T Bruder, John V Forrester,
Andrew D Dick

\begin{abstract}
Aim-To investigate the efficacy of "ex vivo" adenoviral vector mediated gene transfection of human conjunctival epithelial cell as a possible route for gene therapy for the distribution of antiinflammatory agents for the potential treatment of immune mediated ocular inflammatory disorders.
\end{abstract}

Methods-Human conjunctival cells (HCs) were cultured with various concentrations of recombinant adenoviral vectors carrying a reporter gene LacZ, GFP, or an immunomodulating cytokine vIL10. vIL-10 in culture supernatant was detected by sandwich ELISA and biological activity was assessed by suppression of ConA stimulated splenocyte proliferation. $\mathrm{X}$-gal and GFP expression was assessed by histochemistry.

Results-The extent of adenoviral vector mediated transfer of both reporter genes and vIL-10 was dose dependent. LacZ expression could be detected for at least 50 day after infection with multiple of infection (MOI) 200. Following AdCMVvIL-10 transduction, vIL-10 protein expression occurred between 4-6 days posttransduction, and was maintained at a detectable level for at least 1 month. Secreted vIL-10 showed biological activity, significantly inhibiting Con $A$ induced splenocyte proliferation. Additionally, transfection of HCs with two Adv vectors, one carrying $\mathrm{LacZ}$ and the other carrying GFP, resulted in co-expression within a single cell.

Conclusion-These results confirm previous successful adenoviral vector mediated gene transfer to HCs and further show that expression can be maintained. Furthermore the data show HCs can secrete biologically active vIL-10 that could be developed as a strategy to suppress immune mediated disorders. The successful co-transduction of HCs as described for other tissues, opens avenues to develop a multiple target gene therapy locally.

(Br f Ophthalmol 2001;85:861-867)

Compared with other tissue or organs, the development of gene therapy for ocular disease has advantages because the therapeutic effect can be observed ${ }^{1}$ and, consequently, adenoviral vectors have been widely studied in the eye. Direct intraocular application of adenoviral mediated gene transfer can induce expression of reporter genes in different ocular tissues, including corneal endothelium, conjunctiva, iris, lens epithelium, choroid, retina, retinal pigment epithelium, and optic nerve..$^{2-5}$ However, although direct injection of adenoviral vector carrying the LacZ gene into the anterior chamber or vitreous cavity results in a strong expression within the ocular tissue, the long term efficacy of such an approach is limited by immune response to the adenoviral vector. $^{36}$ Despite notions that the eye may protect against immune mediated inflammation, it is likely that intraocular approaches of gene transfer will induce significant immune mediated damage. ${ }^{7}$ For example, injection of brain gliomas with adenovirus vector expressing herpes simplex virus 1 thymidine kinase successfully inhibited syngeneic glioma growth, but also induced chronic active brain inflammation resulting in loss of myelin fibres. ${ }^{8}{ }^{9}$ Generating alternative vectors as well as using an ex vivo approach of gene transfer may restrict any deleterious immune response. As such, the conjunctiva may be an appropriate tissue for such a therapeutic approach. Human adenovirus is highly infectious for both conjunctiva and upper respiratory tract mucosa. ${ }^{1011}$ Adenovirus serotype $A$ to $E$ contain a conserved integrin binding motif (RGD) in their penton base proteins, which combine $\alpha v \beta 5$ integrin as adenoviral receptor on the host cell, ${ }^{12}$ such as the conjunctival epithelial, thus facilitating viral cell entry. ${ }^{13}$

Genetic modification of the conjunctiva with anti-inflammatory cytokines, such as vIL-10, may be of potential value in treating a variety of ocular inflammatory diseases, including uveoretinitis, corneal allograft rejection, and ulcerative keratitis. Previous work has successfully demonstrated reporter gene LacZ expression by cultured human conjunctival epithelial cells. ${ }^{4}$ In rodents, $\mathrm{X}$-gal expression in conjunctiva persisted more than 3 weeks following subconjunctival injection of adenovirus vector. ${ }^{4}$

Previous studies have assumed that transgenes can be highly expressed on HCs thus providing possible therapeutic activity. The aims of this study, therefore, were to (i) assess and confirm the efficacy and duration of transgenes expressed in $\mathrm{HCs}$ in vitro; (ii) assess whether the persistence of secreted vIL-10 is biologically active; and (iii) assess whether transduction of $\mathrm{HCs}$ with more than one adenoviral vector each carrying a different transgene is possible. 

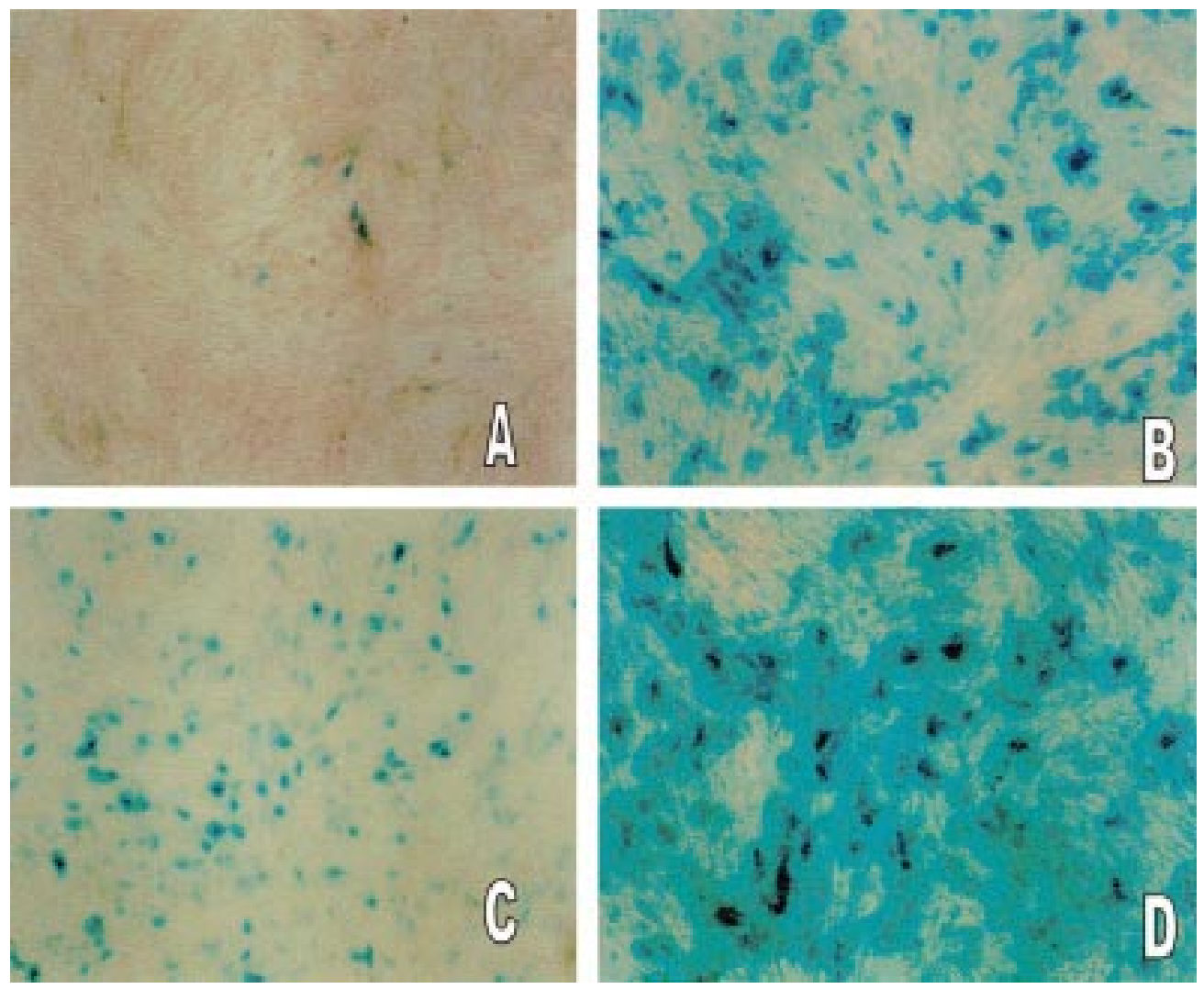

Figure $1 \beta$-gal expression on HCs following AdCMVLacZ transfection. $\beta$-gal activity in HCs 5 days after transduction with AdCMVLacZ at MOI 25 (A), MOI 100 (B), MOI 50 (C), and MOI 200 (D). Magnification $\times 100$.

\section{Materials and methods}

All procedures involving recombinant DNA materials were performed under the guidelines of local genetic modification committee, University of Aberdeen, for the use of adenovirus.

CELL CULTURE

Dulbecco's modified Eagle's medium (DMEM, Sigma, UK) supplemented with $10 \%$ FCS, $2 \mathrm{mM}$ L-glutamine, $100 \mathrm{U} / \mathrm{ml}$ penicillin, $100 \mu \mathrm{g} / \mathrm{ml}$ streptomycin, and $10^{-5} \mathrm{M}$ 2-mercaptoethanol (designated complete DMEM) was used for HCs culture. Human donor eyes were obtained from Amsterdam by material transmission permission. The tissue used was negative for HIV, HCV, CMV, and HBV. After rinsing with phosphate buffered saline (PBS), the conjunctiva was dissected under direct microscopy, and then cut into $2 \times$ $2 \mathrm{~mm}^{2}$ pieces. After two washes in PBS, the conjunctiva was placed in a $35 \mathrm{~mm}^{2}$ culture dish, and digested with $0.25 \%$ trypsin (Difco, UK) for 2 hours at $37^{\circ} \mathrm{C}$. Digestion was stopped by adding complete DMEM. Cells were suspended in $5 \mathrm{ml}$ medium and seeded in $35 \mathrm{~cm}$ flasks and cultured at $37^{\circ} \mathrm{C}$ with $5 \%$ carbon dioxide. Cells were propagated to $70 \%$ confluence and used for transfection between fifth and sixth passage.

ADENOVIRAL VECTORS

Adenoviral vectors expressing green fluorescence protein (GFP) and $\beta$-galactosidase (LacZ) vectors were obtained from Quantum Company (Canada). The viruses were deleted for both $\mathrm{E} 1$ and $\mathrm{E} 3$ regions and so lacked the ability to replicate in non-permissive cells Adenovirus encoding vIL-10 was constructed by $\mathrm{Dr}$ Emri Kovesdi as previously described. ${ }^{14-16}$ In brief, the BCRF-1 coding gene was flanked at the $5^{\prime}$ end with the promotor of the human cytomegalovirus and at the 3' end with SV40 polyadenylation sequence. All viruses were tested and found to have replication competent (RCA) levels of less than 1:1 $\times$ $10^{7}$ plaque forming units (PFU). Viral titres were determined by optical density at $260 \mathrm{~nm}$ ( $1 \mathrm{U}=10^{12}$ viral particles).

TRANSDUCING HUMAN CONJUNCTIVAL CELL WITH ADENOVIRAL VECTOR

Petri dishes of $35 \mathrm{~mm}$ or chamber slides were used to transduce HCs with AdCMVLacZ and AdCMVGFP, and $75 \mathrm{~cm}$ flask for AdCMVvIL-10. Ad1307 a null vector deficient of $\mathrm{cDNA}^{15}$ was used as a control. When HCs were $70 \%$ confluent, adenoviral vector was added at different multiples of infection (MOI). Viral infection was carried out at $37^{\circ} \mathrm{C}$ for 4 hours, and then complete DMEM was added to the cells. Cultures were maintained in a humid atmosphere of $5 \%$ carbon dioxide at $37^{\circ} \mathrm{C}$.

When transfecting with adenoviral vectors, $75 \mathrm{~mm}$ culture dishes were seeded with $2 \times 10^{4}$ HCs. After the cells adhered to the wells (about 3 hours), cells were washed with DMEM to remove non-adherent cells, and then $2 \mathrm{ml}$ fresh complete DMEM was added. The cells were challenged with two adenoviral vectors (AdCMVLacZ and AdCMVGFP) simultaneously. The cells were stained with X-gal at 24 hours 


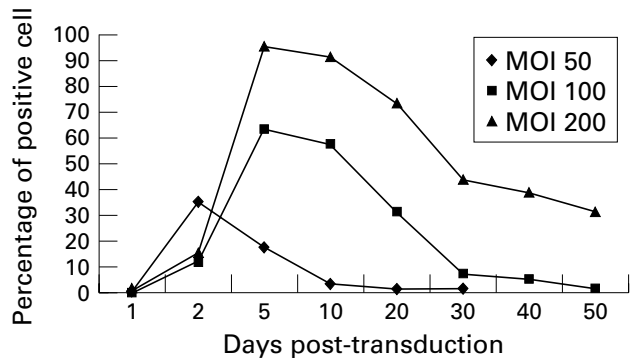

Figure 2 Time course of $\beta$-gal expression after AdCMVLacZ transduction. HCs were transfected with AdCMVLacZ at different MOI. At selected times, the $\beta$-gal expression were determined via $X$-gal staining. Results showed that the maximal expression at MOI 50 was seen at days 2 post-transfection and day 5 for MOI 100 and MOI 200. $\beta$-gal expression was maintained for at least 50 days at MOI 200.

and 48 hours and viewed by fluorescence microscopy. X-gal positive cells, GFP positive cells, and double positive cells were counted in the same field at $\times 100$ magnification. A total of 100 cells/field were counted.

DETECTION OF $\beta$-GALACTOSIDASE ACTIVITY

At different time points, cells were washed with PBS and immediately fixed with $0.05 \%$ glutaraldehyde for 15 minutes at room temperature. Cells were rinsed thoroughly with PBS three times. $\beta$-galactosidase activity was assayed by reacting the cells with $1 \mathrm{mg} / \mathrm{ml}$ 5-bromo-4chloro-3 indolyl $\beta$-gal-D-galactoside (X-gal, Sigma, UK) in a solution containing $50 \mathrm{mM}$ $\mathrm{K}_{3} \mathrm{Fe}(\mathrm{CN})_{6}, 50 \mathrm{mM} \mathrm{K}{ }_{4} \mathrm{Fe}(\mathrm{CN})_{6}$, and $2 \mathrm{mM}$ $\mathrm{MgCl}_{2}$ in $\mathrm{PBS}$ at $37^{\circ} \mathrm{C}$ for 4 hours or overnight.
ELISA ASSAY FOR VIL-10

Supernatants from cultured cells were collected every other day for 30 days. After the supernatants were removed, flasks were washed twice with $2 \mathrm{ml} \mathrm{DMEM}$, and then $2 \mathrm{ml}$ complete DMEM was added. Samples were stored at $-20^{\circ} \mathrm{C}$ until use. $\mathrm{mAb}$ specific for human and viral IL-10, vIL-10 standard and biotinylated anti-human and anti-viral IL-10 $\mathrm{mAb}$ were purchased from Pharmingen (San Diego, USA).

vIL-10 was determined by sandwich ELISA assay. Wells of flat bottom (Nunc, Denmark) microtitre plates were coated with $100 \mathrm{ng}$ of $\mathrm{mAb}$ specific for human and viral IL-10 in carbonate buffer, $\mathrm{pH} 9.0$ at $4{ }^{\circ} \mathrm{C}$ overnight. Following two washes with PBS-0.05\% Tween 20, the plates were blocked with $200 \mu \mathrm{PBS}-10 \%$ BSA for 2 hours at room temperature (RT). After three washes with washing buffer, $100 \mu \mathrm{l}$ of rHuIL-10 standard or cultured supernatants were added and plates were incubated at RT for 2 hours. After five washes, $100 \mu \mathrm{l}$ of biotin conjugated rat anti-human and antiviral IL-10 $\mathrm{mAb}$ was added to each well. After 1 hour of incubation at RT, the plates were washed and incubated at RT with an avidin-peroxidase conjugate. After seven washes, the wells were visualised by adding $100 \mu \mathrm{l}$ of substrate solution (2642KK, PharMingen, USA) for 30 minutes at RT in the dark. The reaction was stopped by adding $50 \mu \mathrm{l} 2 \mathrm{~N} \mathrm{H}_{2} \mathrm{SO}_{4}$ and the plates were read on microplate reader at wavelength $450 \mathrm{~nm}$ (Dynatech RR5000, USA).

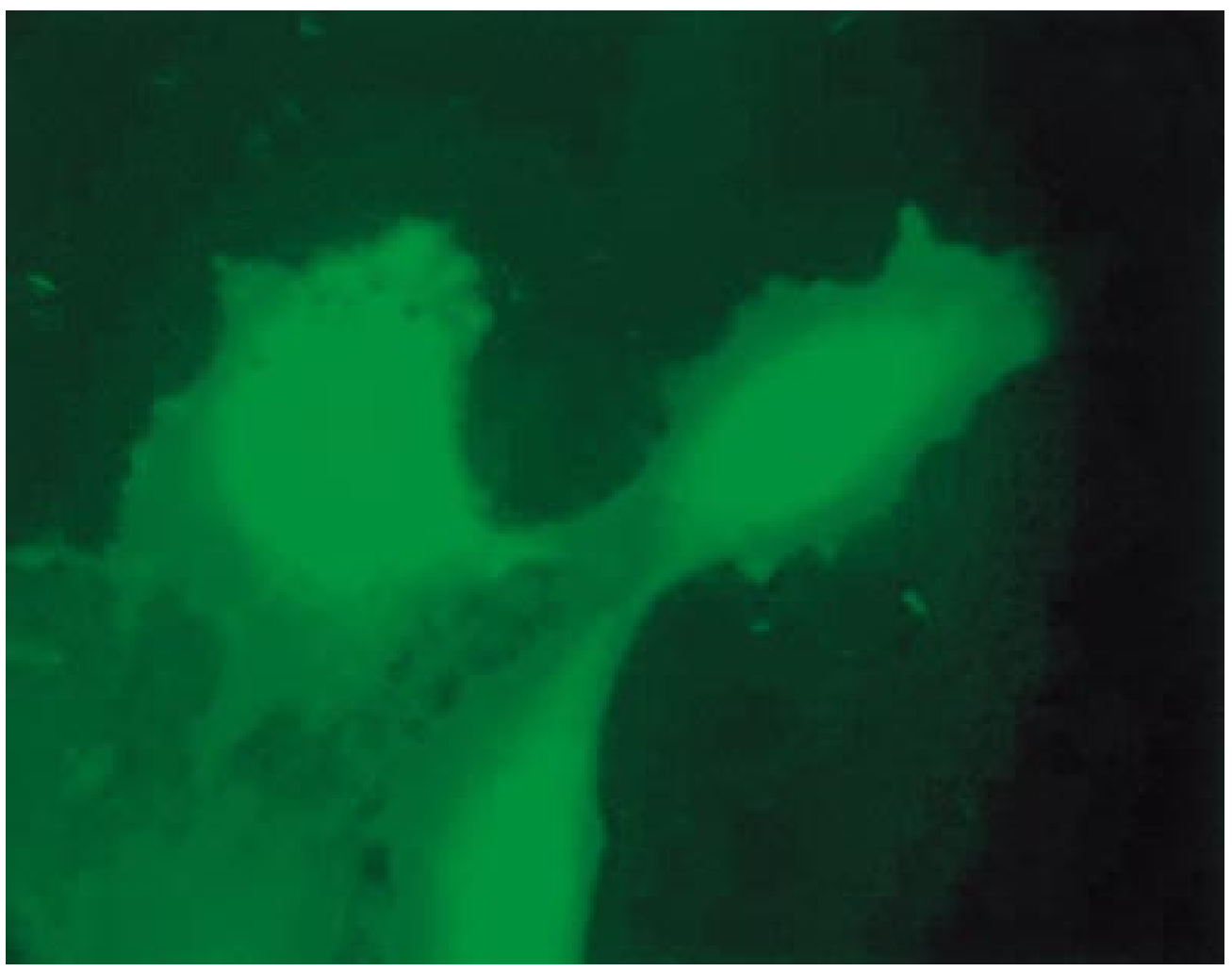

Figure 3 Green fluorescence protein (GFP) expression following HC transfection with AdCMVGFP. 

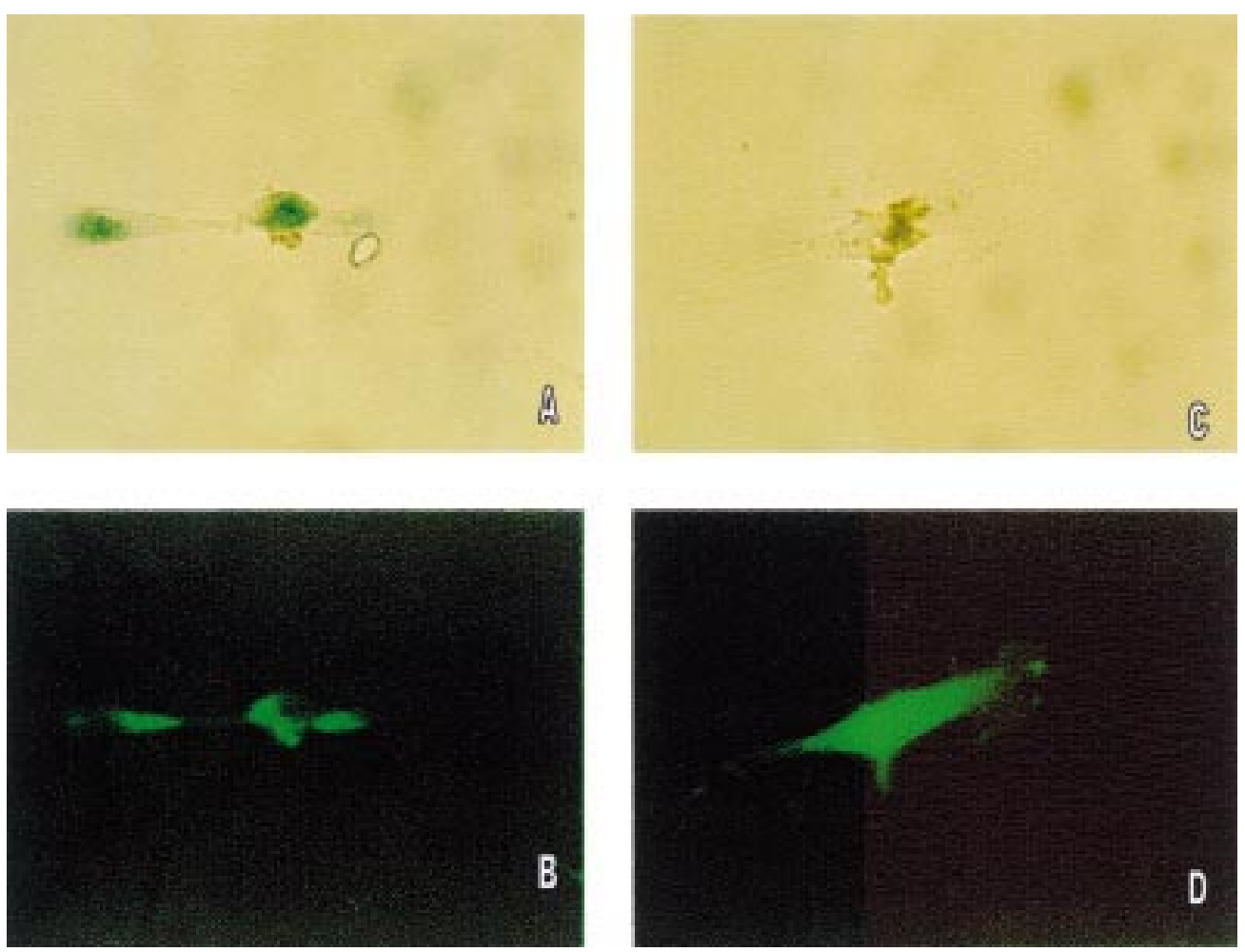

Figure 4 Transduction of HCs with two adenoviral vector carrying $E$ coli LacZ and green fluorescence protein (GFP). ( $A$ and $B$ ) Dual expressing cells. $(C$ and $D) \beta$-gal negative and GFP positive cell. $\beta$-gal expression is mainly nuclear compared with wider distribution of GFP expression. Magnification $\times 400$.

SPLENOCYTE PROLIFERATION ASSAY

Splenocytes were isolated from C57BL/6 mice. Conditioned medium was made as follows: culture supernatant from HCs transduced with or without AdCMVvIL-10 at day 4, 6, 8, and 10 were passed through a $0.2 \mu$ l filter. Splenocytes $2 \times 10^{6}$ in $100 \mu \mathrm{l}$ were seeded in triplicate in a 96 well round bottom plate in the presence or not of $5.0 \mu \mathrm{g} / \mathrm{ml} \mathrm{ConA} \mathrm{(Sigma,} \mathrm{UK),} 100 \mu \mathrm{l}$ of test conditioned medium and/or a neutralising antibody to vIL-10 at concentration 200 ng/ml (Pharmingen, San Diego, CA, USA). Cultures were cultivated for 48 hours, after which $1 \mu \mathrm{l} \mathrm{Ci}{ }^{3} \mathrm{H}$ thymidine was added to each well for a further 18 hours. ${ }^{3} \mathrm{H}$ thymidine incorporation was quantified using a Beckman scintillation counter. Results were expressed as the mean CPM (SD) of triplicate cultures.

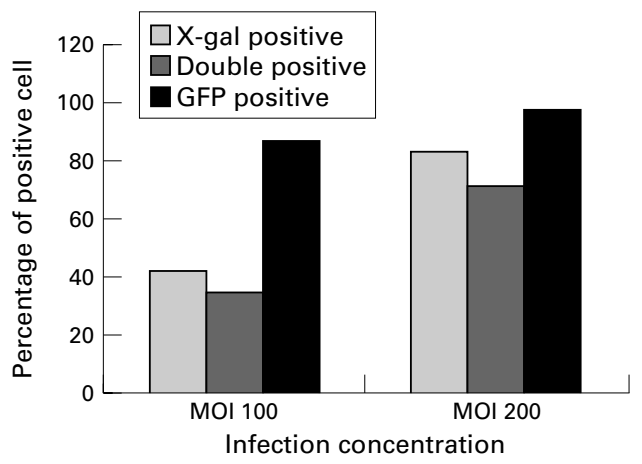

Figure 5 Simultaneous transduction of HCs with AdCMVLacZ and AdCMVGFP. The results are a representative experiment which show that incidence of dual expression was increased with greater MOI.
STATISTICS

Data are represented as mean value (SD). Statistical analysis was carried out using the Student's $t$ test.

\section{Results}

ADENOVIRAL VECTORS EFFECTIVELY TRANSFER EXOGENOUS GENE TO HUMAN CONJUNCTIVAL

CELL

Figure 1 shows $95 \%$ of $\mathrm{HCs}$ exhibited an intense blue staining at 5 days following infection at MOI 200. More than $70 \%$ of the cells at day 20 , and $24 \%$ of cells at day 50 posttransfection, remained X-gal positive. At varying multiples of infection (MOI 50), relatively high levels of LacZ expression in HCs (34\%) were still observed at day 2 post-transfection (Fig 2), although expression rapidly diminished. HCs appeared more sensitive to AdCMVGFP transfection. At MOI 100, nearly 100\% of cells showed strong GFP expression (Fig 3 ).

We next attempted to investigate whether HCs could be infected with two adenoviral vectors carrying independent reporter genes LacZ and GFP. Cells were seeded into $75 \mathrm{~mm}$ petri dishes at $1 \times 10^{4} / \mathrm{ml}$, where cells were transfected with adenoviral vectors at $70 \%$ confluence. The results showed that both reporter genes could be expressed in the same cell. At MOI 100 for each vector, 37\% cells were dual expressing, and $67 \%$ dual expressing cells were observed at MOI 200 cell (Figs 4 and 5). The percentage of GFP expression (both single and dual expressing cells) was significantly higher than X-gal expression $(p<0.01)$. No GFP positive cells were observed in non-transfected HCs. 


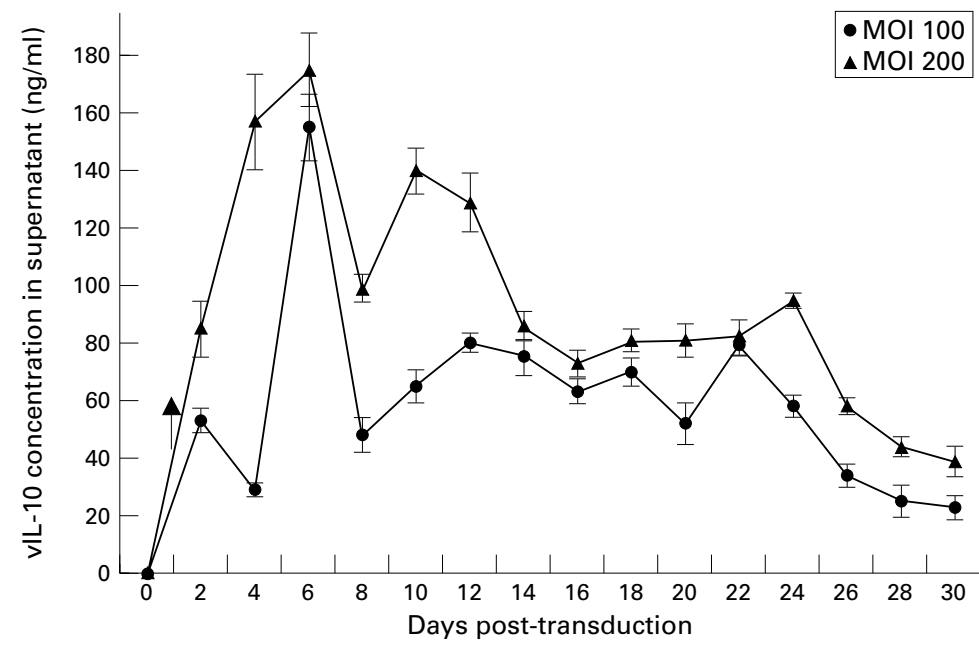

Figure 6 vIL-10 concentration in cultured supernatant of HCs transfected with AdCMVvIL-10. The peak secretion occurred at day 6 post-transfection at both MOI 100 and MOI 200. Although vIL-10 levels declined thereafter, detectable levels were maintained for at least 30 days.
VIL-10 TRANSDUCED HCS SECRETE BIOLOGICALLY ACTIVE VIL-10

Culture supernatants collected every other day for 30 days from $\mathrm{HCs}$ transduced with AdCMVvIL-10 at MOI 200 were assayed by sandwich ELISA. Results are shown in Figure 6. AdCMVvIL-10 infected HCs produced significant quantities of vIL-10 for over 30 days. Maximal secretion occurred at days 4-6 (170 (13) $\mathrm{ng} / \mathrm{ml})$, after which expression decreased but persisted at detectable levels for 30 days (39 (5.3) $\mathrm{ng} / \mathrm{ml}$ )

To assess biological activity, vIL-10 transduced HCs culture supernatant (conditional medium) inhibition of ConA stimulated splenocyte proliferation was determined. The results showed (Fig 7) that secreted vIL-10 significantly inhibited splenocyte proliferation, and anti-vIL-10 mAb reversed vIL-10 mediated suppression of splenocyte proliferation (CPM 9245 (964) v 20049 (1886), p<0.01). No difference in splenocyte proliferation was found in extent of Con A stimulation between the groups where normal supernatant, normal supernatant plus blocking anti-vIL-10 mAb or additional $100 \mu \mathrm{l}$ medium was added ( $\mathrm{p}>0.05)$.

\section{Discussion}

In this study HCs were successfully transduced by adenoviral vectors containing LacZ, GFP and vIL-10. Our results show that HCs genetically modified with AdCMVLacZ, strongly express X-gal in a dose dependent manner and that $\mathrm{X}$-gal expression persisted for up to 50 days at MOI 200. These data confirm recent reports of successful gene transfer to conjunctival cells. In previous reports, this route was potentially more feasible than corneal epithelium. ${ }^{4}{ }^{17}$ Such differences may be related to the distribution of adenoviral receptor, although we have not formally tested this, and direct comparisons of the ability of both routes to suppress immune mediated disorders, including EAU and corneal graft rejection, and the use of other vectors are needed. As these data show that HCs can not only stably express target gene
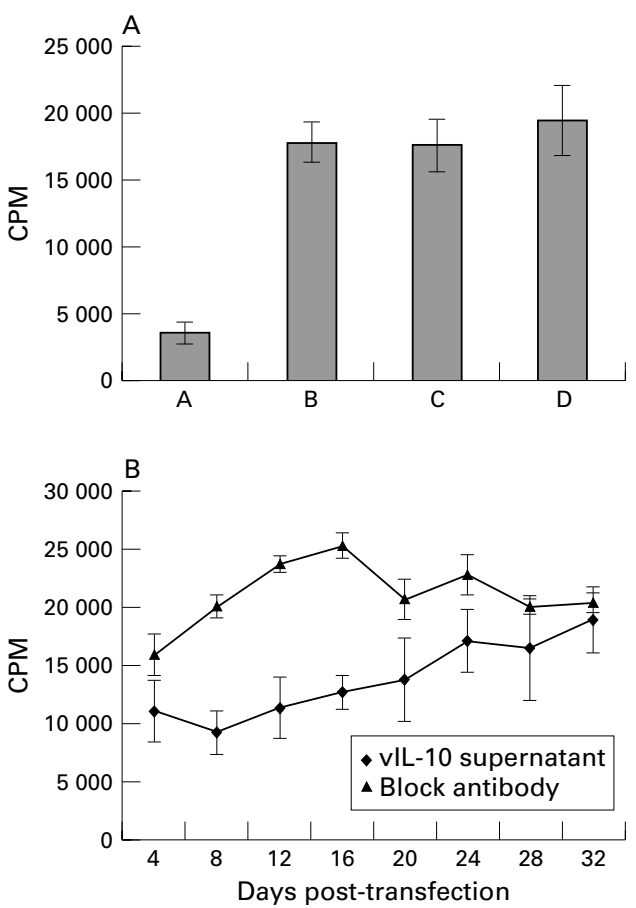

Figure 7 Supernatant of AdCMVvIL-10 transduced HCs significantly inhibited Con A stimulated lymphocyte proliferation. (A) Control groups for splenocyte

proliferation. $A=$ medium alone. $B=C o n A$ stimulated medium plus conditioned medium from non-infected $H C s$ plus blocking anti-vIL-10 $\mathrm{mAb}$. C = Con A stimulated medium plus conditioned medium from non-infected HCs; and $D=$ medium plus Con A. Values represent mean CPM (SD). (B) Con A stimulated splenocyte proliferation was inhibited by supernatant of AdCMVvIL-10 transduced $H C$ throughout days of detectable vIL-10 secretion (see Fig 6). Figure represents mean CPM (SD) for splenocyte proliferation in presence of conditioned medium from AdCMVvIL-10 transduced HCs (vIL-10 supernatant) and conditioned medium plus blocking anti-vIL-10 mAb (anti-vIL-10 mAb). Peak inhibition occurred day 8 post-transfection, that was reversed when IL-10 activity was neutralised with anti-vIL-10 $\mathrm{mAb}$ block ((CPM 9245 (964) v 20049 (1886), $p<0.01$ ). Thereafter, degree of inhibition gradually decreased. By day 32, there was no difference in splenocyte proliferation between controls and AdCMVvIL-10 transduced HCs ( $p>0.05)$.

but also vIL-10, further investigation as a possible ex vivo gene therapeutic approach for management of inflammatory eye disease following a similar strategy described for other tissues is warranted. ${ }^{18}$

vIL-10, the IL-10 homologue of EpsteinBarr virus, has anti-inflammatory activity similar to human IL-10. vIL-10 downregulates MHC class II, ICAM-1, and B7 expression on macrophages and dendritic cells, ${ }^{19}$ inhibits $\mathrm{T}$ cell activation and alloreactivity, and cell adhesion molecule expression ${ }^{20}{ }^{21}$ thus suppressing inflammation. Additionally, vIL-10 suppresses proinflammatory cytokines (TNF- $\alpha$ and IL$1 \beta$ ) production. ${ }^{22}$ As such, results have shown that transfer of vIL-10 by adenoviral vectors or retroviral vector prolonged organ graft survival and greatly reduced leucocyte infiltration into cartilage in experimental arthritis. ${ }^{23-27}$ These data show that AdCMVvIL-10 transduction of HCs resulted in an early high peak of biologically active vIL-10 that was maintained despite reduced levels of vIL-10 for over 20 days. 
Ocular inflammation and corneal allograft rejection are complex pathophysiological processes that involve multiple mediators such as cytokines, chemokines, and growth factors. ${ }^{28}$ However, blockade of one inflammatory cytokine or induction of cytokine antagonist may not be adequate to suppress inflammatory responses or induce a prolonged therapeutic effect. Using AO to PVG rat orthotopic keratoplasty model, Torres et al recently demonstrated that injection of murine IL-10 subconjunctivally did not prolong corneal allograft survival and may have even have accelerated rejection. ${ }^{29}$ An arguable future approach, therefore, is to target two or more regulators of the immune response. There has been success by blocking more than one co-stimulatory signal via CTLA4-Ig and anti-CD40L mAb, where both suppression and long term tolerance was induced. ${ }^{30}$ Technically, however, achieving this by gene therapy is problematic. Although it is difficult to clone more than one target gene in one vector because the capacity of insertion is limited, there has encouragingly been progress made in generating multiple gene transfer within a single vector. ${ }^{31} 32$ In addition, intratumoral co-injection of two adenoviral vectors one encoding IFN $-\gamma$ inducible protein-10 and the other encoding IL-12 resulted in marked antitumoral synergy. ${ }^{33}$ Similarly, successful antitumoral activity has been demonstrated with concomitant adenoviral delivery of IL-2 and IL-12. ${ }^{34}$

Our present data showed that both reporter genes could be expressed in HCs, although the efficacy of expression appeared dependent upon the reporter gene. As it is clear that two simultaneous adenoviral vectors can mediate independent gene delivery to the same cell, further development of dual vector delivery to resident ocular surface cells will potentially lead to the development of long term immunomodulatory strategies. Previous reports ${ }^{4}$ have shown successful Adv vector gene delivery to $\mathrm{HC}$, and indirectly commented on potential cytopathogenicity by noting increased IL- 6 , IL- 8 , and ICAM-1 expression that could in turn be suppressed by concomitant topical steroid therapy. It is likely, however, that despite the efficiency of Adv vector gene delivery, the generation of $\mathrm{Adv}$ vector used in these studies will not be clinically pertinent because of the potential inflammatory response. ${ }^{3}$ However, as this extraocular route can secrete immunomodulatory products it may provide a strategy to limit intraocular damage while maintaining a therapeutic effect. In conclusion, these data show that transduction of $\mathrm{HCs}$ with recombinant adenoviral vectors can result in high levels of stable target gene expression with biological activity and simultaneous transduction of HCs with two reporter genes results in dual gene expression within one cell. Such an approach warrants further investigation to elicit any putative clinical application, particularly for ocular surface disorders, including corneal allograft rejection and non-infectious inflammatory disease.

This work was supported by the Royal Society of UK. JS is the recipient of a Sino-British Trust Fellowship from the Funds.
1 Okada AA, Forrester JV. Ocular inflammatory disease in the new millennium. Arch Ophthalmol 2000;118:116-19.

2 Reichel MB, Hudde T, Ali RR, et al. Gene transfer in ophthalmology Ophthalmologe 1999;96:570-7.

3 Reichel MB, Hudde T, Ali RR, et al. Immune responses limit adenovirally mediated gene expression in the adult mouse eye. Gene Ther 1998;5:1038-46.

4 Tsubota K, Inoue $\mathrm{H}$, Ando K, et al. Adenovirus-mediated gene transfer to the ocular surface epithelium. Exp Eye Res 1998;67:531-8

5 Mashhour B. Gene therapy in ophthalmology. Bull Acad Natl Med 1996;180:645-57.

6 Mashhour B, Couton D, Perricaudet M, et al. In vivo adenovirus-mediated gene transfer into ocular tissues. Gene Ther 1994;1:122-6.

7 Cordeiro MF, Schultz GS, Ali RR, et al. Molecular therapy in ocular wound healing. Br f Ophthalmol 1999;83:121924.

8 Dewey RA, Morrissey G, Cowsill CM, et al. Chronic brain inflammation and persistent herpes simplex virus 1 thymidine kinase expression in survivors of syngeneic glioma treated by adenovirus-mediated gene therapy:implications treated by adenovirus-mediated gene therap

9 Kielian T, Hickey WF. Inflammatory thoughts about glioma gene therapy. Nat Med 1999;5:1237-8.

10 Kowalski RP, Karenchak LM, Romanowski EG, et al. Evaluation of the shell vial technique for detection of ocular adenovirus. Community Ophthalmologists of Pittsburgh, Pennsylvania. Ophthalmology 1999;106:1324-7.

11 Takeuchi S, Itoh N, Uchio E, et al. Serotyping of adenoviruses on conjunctival scrapings by PCR and sequence analysis. F Clin Microbiol 1999;37:1839-45.

12 Mathias P, Galleno M, Nemerow GR. Interactions of soluble recombinant integrin $\alpha \mathrm{v} \beta 5$ with human adenoviruses. $\mathcal{F}$ Vir 1998;72:8669-75.

13 Rayner SA, Gallop JL, George AJ, et al. Distribution of integrins $\alpha v \beta 5, \alpha v \beta 3$ and $\alpha \mathrm{v}$ in normal human cornea: possible implications in clinical and therapeutic adenoviral infection. Eye 1998;12:273-7.

14 Qin L, Chavin KD, Ding Y, et al. Multiple vectors effectively achieve gene transfer in a murine cardiac transplantation model. Immunosuppression with TGF-beta 1 or vIL-10. Transplantation 1995;59:809-16.

15 Brough DE, Hsu C, Kulesa VA, et al. Activation of transgene expression by early 4 is responsible for a high level of persistent transgene expression from adenovirus vectors in sistent transgene expression fron
vivo. F Virol 1997; 71:9206-13.

16 Whalen JD, Lechman EL, Carlos CA, et al. Adenoviral transfer of the viral IL-10 gene periarticularly to mouse paws suppresses development of collagen-induced arthritis in both injected and uninjected paws. F Immunol 1999;162: 3625-32.

17 Oral HB, Larkin DF, Fehervari Z, et al. Ex vivo adenovirusmediated gene transfer and immunomodulatory protein production in human cornea. Gene Ther 1997;4:639-47.

18 Ikeda T, Kubo T, Nakanishi T, et al. Ex vivo gene delivery using an adenovirus vector in treatment for cartilage defects. F Rheumatol 2000;27:990-6.

19 Lechman ER, Jaffurs D, Ghivizzani SC, et al. Direct adenoviral gene transfer of viral IL-10 to rabbit knees with experimental arthritis ameliorates disease in both injected and contralateral control knees. $f$ Immunol 1999;163: 2202-8.

20 Drazan KE, Wu L, Olthoff KM, et al. Transduction of hepatic allografts achieves local levels of viral IL-10 which suppress alloreactivity in vitro. F Surg Res 1995;59:219-23.

21 Henke PK, DeBrunye LA, Strieter RM, et al. Viral IL-10 gene transfer decreases inflammation and cell adhesion molecule expression in a rat model of venous thrombosis. $\mathcal{F}$ Immunol 2000;164:2131-41.

22 Drazan KE, Wu L, Bullington D, et al. Viral IL-10 gene therapy inhibits TNF-alpha and IL- 1 beta, not IL-6, in the newborn endotoxemic mouse. F Pediatr Surg 1996;31:41114.

$23 \mathrm{Kim} \mathrm{KN}$, Watanabe S, Ma Y, et al. Viral IL-10 and soluble TNF receptor act synergistically to inhibit collagennduced arthritis following adenovirus-mediated gene transfer. F Immunol $2000 ; 164: 1576-81$.

24 Jorgensen C, Apparailly F, Canovas F, et al. Systemic viral interleukin-10 gene delivery prevents cartilage invasion by human rheumatoid synovial tissue engrafted in SCID mice. Arthritis Rheum 1999;42:678-85.

25 Whalen JD, Lechman EL, Carlos CA, et al. Adenoviral transfer of the viral IL-10 gene periarticularly to mouse paws suppresses development of collagen-induced arthritis in both injected and uninjected paws. F Immunol 1999;162: in both inject.

26 Qin L, Chavin KD, Ding Y, et al. Retrovirus-mediated transfer of viral IL-10 gene prolongs murine cardiac allograft survival. F Immunol 1996;156:2316-23.

27 DeBruyne LA, Li K, Chan SY, et al. Lipid-mediated gene transfer of viral IL-10 prolongs vascularized cardiac allograft survival by inhibiting donor-specific cellular and humoral immune responses. Gene Ther 1998;5:1079-87.

28 Dick $\mathrm{AD}$, Isaacs JD. Immunomodulation of autoimmune responses with monoclonal antibodies and immunoadhesins: treatment of ocular inflammatory disease in the next millennium. Br f Ophthalmol 1999;83: 1230-4.

29 Torres PF, de Vos AF, Martins B, et al. Interleukin 10 treatment does not prolong experimental corneal allograft survival. Ophthalmic Res 1999;31:297-303. 
$30 \mathrm{Li} \mathrm{Y,} \mathrm{Li} \mathrm{XC,} \mathrm{Zheng} \mathrm{XX,} \mathrm{et} \mathrm{al.} \mathrm{Blocking} \mathrm{both} \mathrm{signal} 1$ and signal 2 of T-cell activation prevents apoptosis of alloreactive $\mathrm{T}$ cells and induction of

31 Chen P, Tian J, Kovesdi I, et al. Interaction of the adenovirus 14.7-kDa protein with FLICE inhibits Fas ligandinduced apoptosis. Biol Chem 1998;273:5815-20.

32 Bruder JT, Jie T, McVey DL, et al. Expression of gp $19 \mathrm{~K}$ ncreases the persistence of transgene expression from an adenovirus vector in the mouse lung and liver. 7 Virol 1997;71:7623-8.
33 Narvaiza I, Mazzolini G, Barajas $M$, et al. Intratumoral coinjection of two adenoviruses, one encoding the chemokine IFN-gamma-inducible protein-10 and another encoding IL-12, results in marked antitumoral synergy. F Immunol 2000;164:3112-22.

34 Hirschowitz EA, Naama HA, Evoy D, et al. Regional treatment of hepatic micrometastasis by adenovirus vectormediated delivery of interleukin-2 and interleukin-12 cDNAs to the hepatic parenchyma. Cancer Gene Ther 1999;6:491-8.

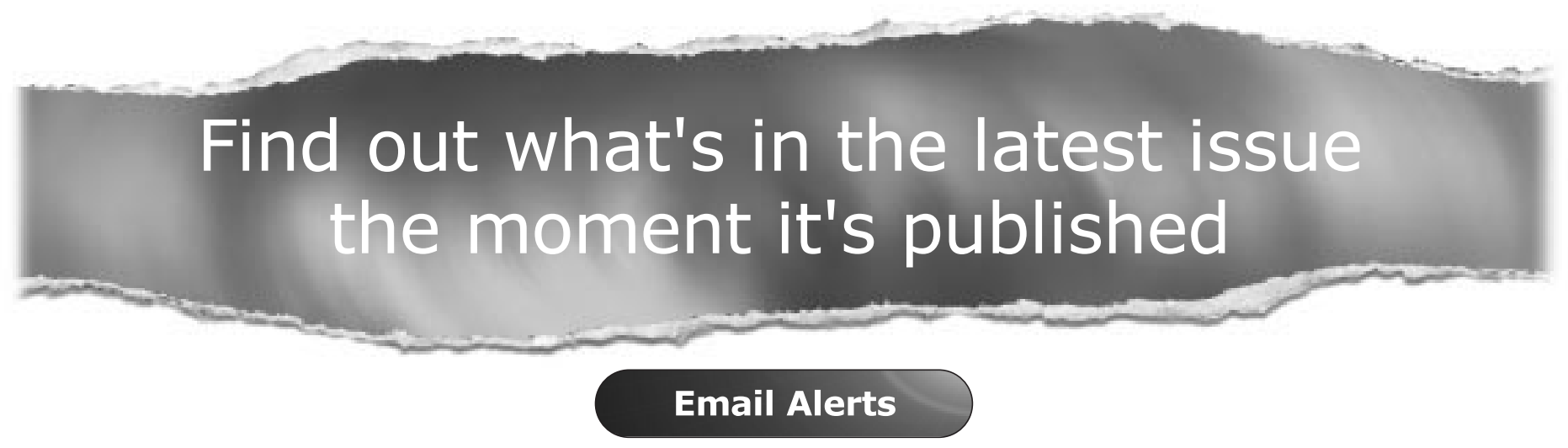

Sign up to receive the table of contents by email every month. You can select from three alerts: Table of Contents (full), TOC Awareness (notice only); British Journal of Ophthalmology related announcements.

\section{www.bjophthalmol.com}

